\title{
Réquiem por Yarini ¿Una tragédia griega cubana?
}

\author{
ELINA MIRANDA CANCELA \\ Departamento de Lingüística y Letras Clásicas \\ Facultad de Artes y Letras \\ Universidad de La Habana
}

\begin{abstract}
RESUMO: Carlos Felipe (1914-1975) foi um dos fundadores da dramaturgia cubana contemporânea, junto com Virgilio Piñera e Rolando Ferrer, mas enquanto Piñera tomava o mito como assunto da sua primeira obra, Electra Garrigó, Felipe já durante anos tinha a idéia de converter a morte de Alberto Yarini, a personagem histórica que se transformou em lenda nos bairros marginais tão bem conhecidos pelo autor, em ponto de partida de uma obra que foi o que ele chamou uma "tragedia grega cubana". Nosso trabalho analisa a maneira com Carlos Felipe tratou o assunto para fazê-lo um mito, a forma em que estruturou a sua obra conforme a tragédia, os recursos e conceitos trágicos que utilizou para chegar até o seu propósito, sobretudo para lograr que o seu "Requiem por Yarini" seja uma peça antológica do teatro cubano.
\end{abstract}

PALAVRAS-CHAVE: Carlos Felipe, Réquiem por Yarini, tragédia grega, teatro cubano, literatura comparada.

Mucho se ha especulado por teóricos y críticos qué es lo trágico y qué se ha de entender por tragedia, pero no es menos cierto que el paradigma por excelencia sigue siendo la tragedia griega, tal como se plasmó entre los atenienses del siglo $\mathrm{V}$ a.n.e., al extremo que si para muchos el epíteto no es necesario, otros lo emplean a manera de sintagma ya totalmente lexicalizado, como lo hiciera Carlos Felipe cuando le confesó a Armando Suárez del Villar que lo obsesionante para él en la muerte de Alberto Yarini era la idea de que era un tema "para hacer la tragedia griega cubana".'

A la atracción que durante siglos ha ejercido el antiguo teatro griego, no se sustrajeron, sobre todo en la primera mitad de este siglo XX, quienes conformaron un nuevo teatro acorde con las inquietudes contemporáneas. A semejanza de los antiguos trágicos griegos, el interés de estos dramaturgos se centraba, no en los hechos propiamente, sino en su significación e interpretación. Por ello, el uso de los viejos mitos, con su carga polisémica y aún pregnante, enriquecidos por una larga tradición teatral, les facilitaba su propia expresión y la búsqueda de una verdadera comprensión de la contemporaneidad, al tiempo que suponían un reto y un acicate para su labor como creadores. A este "bácilo griego", como el mismo lo llamara, no se pudo oponer nuestro Virgilio Piñera, que en 1941 escribe Electra Garrigó, aunque no se estrenara hasta el añe 1949.

Pero el renovado acercamiento a la tradición clásica que se advierte en este siglo, asume también otra dirección de signo contrario: El mitologizar lo contemporáneo, el encuadrar dentro 
de las viejas estructuras el acontecer reciente, de modo que se devele su sentido profundo y se ahonde en su significado trascendente.

En particular, el afán de revitalizar la antigua tragedia, de lograr apresar la dimensión trágica del acaecer contemporáneo en un género dramático que reasuma funciones semejantes a las puestas de manifiesto en la escena ateniense, ha estado presente en grandes autores de todos los tiempos, pero adquiere especial relieve en nuestro siglo, descubridor del psicoanálisis, del inconsciente colectivo y de otras tantas teorías; época de un avance científico arrollador y de confrontaciones sociales de carácter mundial, donde los conflictos del ser humano y su realización alcanzan un grado de complejidad y de intensidad antes no previsibles.

En este contexto no es de extrañar que también en Cuba quienes se sienten apremiados por la necesidad de proyectar nuestra dramaturgia a escala de los tiempos que corren, recurran a la tradición clásica como fuente de contemporaneidad, más si tenemos en mente que precisamente en 1941 nace Teatro Universitario.

Este, bajo la dirección de Ludwig Shajowicz, hace resonar los versos de los viejos trágicos bajo nuestro sol tropical en los pórticos universitarios. Como bien rememora Alejo Carpentier en su Consagración de la Primavera, surge un teatro que "sin pasar por una tímida preparación a base de pasos de comedia o de entremeses cervantinos, ha preferido apuntar a lo alto desde el comienzo, montando intrépidamente a sus actores en coturnos de Eteocles, el Heraldo y el Mensajero, envolviendo a sus criollas actrices en los velos de Antígona y de Ismena" (Carpentier, 1979, p.203).

La tradición se desempolva en esa década del 40 , también en nuestro ámbito cultural, no ya por la lectura de autores europeos y norteamericanos, sino porque se hace parte de la vida cotidiana de quienes, como los personajes carpenterianos, transitan por el recinto universitario y sienten resonar en los versos que se esparcen en la colina, sus propias preocupaciones.

Cuando Federico García Lorca, al referirse a su Yerma, la definía: "Una tragedia con cuatro personajes principales y coro, como han de ser las tragedias. Hay que volver a la tragedia" (Lorca, 1962, p.1709), se hacía eco de un sentir que estaba presente en muchos dramaturgos de la época y al cual no fue ajeno Carlos Felipe, a quien sus vecinos del barrio de Jesús María y trabajadores del puerto o la aduana, no identificaban con aquel Carlos Fernández, compañero de faenas y vicisitudes.

En efecto, nacido en 1914 y miembro de una familia pobre y trabajadora, vecina de uno de los barrios cercanos al Castillo de Atarés, en el ambiente de los muelles de la bahía de La Habana, Carlos Fernández poco se diferenciaba de otros muchachos que muy pronto tuvieron que abandonar las aulas y ponerse a trabajar para ayudar a sus familias, siempre en situación precaria, si no fuera por su interés por el teatro.

Años después, cuando ya se le conocía como Carlos Felipe, contaba que aproximadamente a los quince años decidió saber qué era un teatro. Con sus escasos ahorros, pero con mucha emoción compró un billete en el Actualidades para ver una Pasionaria, de Cano, pero lo que de verdad lo deslumbró fue la ópera Rigoletto; sin embargo, su noche decisiva sería unos años después, al presenciar la actuación de Margarita Xirgu en Bodas de Sangre. Aseguraba Carlos Felipe que sintió fiebre, al tiempo que comprendía que el teatro era su vida. Quería hacer teatro, pero este tenía que ser cubano.

Su opción le sirve de estímulo para tratar de completar su educación de forma autodidacta. Mientras trabaja, primero como camarero y después, durante veintisiete años, como empleado de aduana, estudia Gramática y Armonía Musical, inglés y francés, entre otras materias; lee a Shakespeare, los clásicos de los Siglos de Oro y cuantas obras y cuantas historias de la literatura le caen en las manos. Por su conocimiento del inglés y francés se mantiene al día de todo lo que sucede en los escenarios del mundo, y aprende italiano par leer a Pirandello en su lengua original. 
Por sus lecturas se familiariza con el teatro, en su historia, en sus técnicas y en sus principales tendencias; por su quehacer cotidiano, junto a la gente del barrio de San Isidro, se adentra en el mundo de los muelles, de los marineros y de los marginales -prostitutas, chulos, tahúres-, para quienes Alberto Yarini y Ponce de León, en su breve paso por el barrio ya era toda una leyenda. Buscará Carlos Felipe conjugar en su obra teatral lecturas y vivencias, y a lo largo de unos veinte años no le abandonará la idea de escribir su tragedia cubana en torno a la muerte del proxeneta más famoso de La Habana.

Cuenta el propio autor que desde 1934 "venía oyendo hablar de Yarini a las putas, a la gente de los muelles, a los estibadores, que casi todos eran abacuá, y también a los dependientes de los café que ya eran viejos en esta época y lo conocieron bien a él y a los franceses".

Por los tiempos en que manda un acto de una pieza teatral al concurso de $A D A D$ y finalmente gana el premio con El chino, en 1947, ya por entonces andaba escribiendo su obra sobre Yarini, a la que llamaba El gallo. Abandona el proyecto, porque entre las opiniones de su hermana Rosa y la prohibición de que El chino fuera presentado en México, se convence de que este asunto no iba a tener aceptación. En 1954 el encuentro con una prostituta que había sido "de las de Yarini", y sus recuerdos, le hacen retomar El gallo. Lo rebautiza como El Rey de la zona y sobre la base del testimonio de la prostituta, la nueva versión se centra en un triángulo de amores protectores de Yarini: el de Ismael Prado, su guardaespaldas, el de la Jabá y el de la Santiaguera. Mas, de nuevo la influencia de la hermana Rosa asegura que jamás la obra será aceptada por inmoral, se impone y una vez más es abandonada. No será, pues hasta 1958 que le de su título definitivo, Réquiem por Yarini, y hasta 1960 que la considere terminada y la publique, aunque su estreno solo se produzca cinco años más tarde.

No obstante la demora, tanta que en el interim estrena otras tres obras - El chino en 1947, Capricho en rojo, en 1950 y El travieso Jimmy, en 1959-, siempre como él mismo dice, "volvía a escribir y a escribir en mis libretas para Yarini". Así pues, aunque oficialmente la obra data de 1960, tenemos que considerarla, al menos pergeñada, desde la década del cuarenta, y a pesar de que el autor aduce como causa que le frenara una y otra vez los prejuicios que no admitiría en escena la vida de un burdel o motivaciones de índole homosexual en la admiración de Ismael Prado, tal como pensara presentarlo en El rey de la zona; cabría preguntarse hasta qué punto en esas versiones Carlos Felipe no sentía logrado su propósito, al tiempo que con las sucesivas reelaboraciones su propia interpretación ganaba en perspectiva trágica.

En la obra de Carlos Felipe, siempre encontramos a manera de motivo reiterado, un deseo de recuperar el pasado, como bien apunta Rine Leal (Leal, 1967, p. 195), un momento en que los personajes, por muy sórdida que haya sido su existencia, se sintieron vitalmente realizados. Y de la forma en que Carlos Felipe entra en contacto con Yarini, se colige que ese momento fundamental para el barrio de San Isidro, para los hombres y mujeres del puerto con los que precisamente ese nexo el que destaca, cuando quiere explicar la razón de que en la muerte de este personaje percibiera un tema propio de tragedia, "porque ese hombre era querido por todo el muelle; el entierro de él lo recuerda la gente muy vieja de allí como el más grande después del de Chibás".

Por tanto, para Carlos Felipe lo importante era la leyenda conformada, pues al igual que sucedía con los héroes míticos en la antigua Grecia, lo fundamental no es el sujeto histórico, el punto de partida, sino el prestigio mítico que lo transforma en el más alto exponente de esa sociedad, al tiempo que la caída del héroe brindaba al trágico griego la posibilidad de cuestionarse su comportamiento e indagar el porqué de su actuación.

La tragedia griega se basaba fundamentalmente en asuntos míticos. Solo conservamos una pieza, Los persas, de Esquilo, en que el hecho histórico toma el lugar del mito, aunque hay noticias de algunas más; pero esta obra nos permite advertir que para el poeta trágico no hay diferencias en el tratamiento de uno y otro. No le interesa a Esquilo presentar lo sucedido, sino 
que se cuestiona sobre las razones de la derrota persa y en toda la obra procura poner de manifiesto ante el espectador su interpretación de los hechos, de la misma manera que cuando en Los siete contra Tebas toma como asunto el fin de la mítica estirpe de Edipo, la lejanía temporal propia del mito, se suple, por la distancia geográfica, así como por la diferencia de usos y costumbres. Sin olvidar que para el ateniense de la época las fronteras entre mito e historia se perdían en cuanto a su pasado se refería, el acontecimiento histórico de relevancia vital para la ciudad funciona para el trágico en la misma perspectiva que el mito.

Carlos Felipe busca también esta separación de los sucesos históricos. Su Yarini se llama Alejandro y poco importan sus antecedentes familiares o sus vínculos con la política de la época o cualquier otra particularidad de la vida de Alberto Yarini y Ponce de León. El personaje Alejandro Yarini solo cobra vida en el recinto cerrado del prostíbulo, en ese mundo de relaciones, normas y mecanismos propios, del que la Jabá se erige como guardiana y protectora. Sólo se alude al mundo exterior como fuente de asechanzas y peligros frente al cual, como ha señalado Graziella Pogolotti, "el prostíbulo se convierte en fortaleza bien defendida, donde la acción de cada día se ha hecho ritual" (Pogolotti, 1980, p.17).

A partir de los recuerdos de personas que lo habían conocido, quienes al mirar atrás magnifican el porte, los aires señoriales y las normas establecidas por Yarini; a partir de la leyenda que se había conformado entre los vecinos del barrio, para quienes los tiempos de Yarini constituían la belle époque de San Isidro, el momento del pasado significativo, en el cual sus calles, sus casas, su gente, habían cobrado una luz particular, Carlos Felipe mitifica la realidad, y a juzgar por los títulos y los comentarios del autor, parece que este proceso transcurre desde la atracción por el personaje en sí, El Gallo, hasta la comprensión del significado de Yarini para su zona y de ahí la conversión de su obra en un réquiem: "fue en 1958" le comenta a Suárez del Villar, "cuando se me ocurre cambiarle el nombre y ponerle Réquiem por Yarini. Esto, cuando se publica en 1960 es criticado por algunos extremistas, porque hacerle un réquiem a un chulo es ponerlo como símbolo y yo le pongo Réquiem por Yarini porque los chulos con él desaparecieron y con la Revolución desapareció la caricatura de los chulos".

Compenetrado con su humilde barrio, donde se daba la mano el obrero, con sus altibajos laborales, el empleado de pequeños comercios, el modesto trabajador por cuenta propia, el hombre de mar y quien vive al márgen de la sociedad establecida, Carlos Felipe proyecta sus valores de modo tal que, como advirtiera Graziella Pogolotti, forja "la imagen de una cultura de la resistencia" (Pogolotti, 1980, p.16) y abre una vertiente de indudable repercusión en el teatro cubano posterior. Baste recordar Santa Camila de La Habana Vieja (José Brene, 1962) o María Antonia (Eugenio Hernández Espinosa, 1967), al tiempo que el nexo tendido entre Yarini y este ámbito social, le permite al personaje ganar en dimensión trágica, en tanto la acción del héroe en la antigua tragedia implica siempre el vínculo con la colectividad, aunque este se manifieste de disímiles maneras.

Al percibir en la historia de Yarini un tema de tragedia griega, ello tuvo que repercutir necesariamente en el modo de estructurar la obra de acuerdo con los cánones del género. Estár: presentes las famosas unidades que deben más en su implantación como normas imprescindibles a los neoclásicos franceses que a Aristóteles, a quién tradicionalmente se le atribuye su paternidad, y que en verdad en su Poética se limitó a dejar constancia de lo que advertían como generalidad al teorizar sobre una práctica teatral de más de un siglo.

Toda la acción se desarrolla, pues, en el limitado espacio del salón del prostíbulo y en unas cuantas horas del día 22 de noviembre de 1910. Cuando la obra comienza, un ambiente de temor inquietud y peligro se cierne sobre sus moradores. La hora decisiva de Yarini se acerca. La vida del burdel, el orden creado está amenazado. Al igual que entre los griegos, poco importan los antecedentes, los hechos que han condicionado este momento; lo fundamental es la situación conflictiva que involucra la propia existencia. 
Aunque la obra se divide en tres actos, siguiendo los usos contemporáneos, Rine Leal asienta que Carlos Felipe ha puesto los telones por concesión a su público no acostumbrado "a suportar dos horas de función sin levantarse de su butaca" (Leal, 1967, p.197), puesto que su ideal sería la representación corrida, como en el teatro antiguo. Concentración de la acción, pocos personajes y si bien no hay coro, como deseara García Lorca, el autor utiliza determinadas partes, escenas de la obra, con funciones semejantes a las desempeñadas por el coro trágico. Con ellas se pone de relieve que bajo la estructura externa usual entre los modernos, subyace, al menos de forma latente, la antigua configuración trágica.

A manera de prólogo, en las primeras escenas de la obra, la Jabá no solo introduce al espectador en el cerrado mundo del burdel con sus leyes y normas, en el que Yarini alcanza su posición y se torna un mito, sino que a través de sus temores, se manifiesta las asechanzas que pueden terminar con ese orden que en parte ella encarna y en parte ella guarda, como justificación última de su propia vida, aunque en principio no tenga plena conciencia de ello.

La Santiaguera, Lotot y Palacio -el amor, la rivalidad, el poder político- son las fuentes de un peligro que el anuncio divino de la posible muerte de Yarini -a través del uso de la práctica de la santería, la adivinación mediante los caracoles, y Bebo la Reposa-, deviene inminente. La Jabá, con el poder en ella depositado por las fuerzas que rigen el círculo de su existir, toma todas las medidas tanto en el plano humano como el divino, pero el ambiente de incertidumbre no se despeja: la supervivencia de este mundo está en juego.

Con la llegada de la Dama de Velo y la Santiaguera se produce un contrapunteo entre esta especie de extranjera, esta mujer de otro ambiente, y las del burdel, mediante la contraposición de los pensamientos de la primera, en apartes, y el diálogo entre la Jabá y la Santiaguera. Sirven estas escenas de distensión en relación con el conflicto recién presentado, al tiempo que completan la imagen de Yarini, se expone la posibilidade de ruptura del orden representado por la Jabá ante ios embates de la Santiaguera, ya aludida en el "prólogo", y se hace evidente, entre las diferencias manifiestas de estas tres mujeres, el nexo de identidad subrayado por la Jabá al concluir "somos iguales": la subordinación al hombre, que las tres aceptan como parte de un orden inapelable, aunque desde posiciones distintas. Por tanto estas escenas, con su alejamiento de la acción, con su diálogo en contrapunto y la reflexión que conlleva, sin obviar que complementan y redondean, la situación antes esbozada, cumplen funciones análogas a la propia de la párodos de la estructura trágica, a pesar de la ausencia coral.

Siguiendo el paralelo con el esquema presente en muchas tragedias, la última parte de este primer acto conforma lo que hubiera podido ser el primer episodio de una tragedia, con la salida a escena del personaje del que ya hemos oído hablar y caracterizar a través de la óptica de la Jabá, Ismael, la Santiaguera, la Dama de Velo, pero que ahora cobra cuerpo como centro o cúspide de una jerarquía de relaciones, normas y ritos que ilumina y justifica la sórdida vida del prostíbulo. Como bien había dicho la Jabá: "Yarini el político nada significa; Yarini el tahúr no es gran cosa, te lo digo yo que conozco suas mañas. Ah, pero Yarini el chulo...! Yarini el chulo es el Rey!" (Carlos Felipe, 1967, p.194).

Yarini nos es presentado en su momento de mayor esplendor. El carácter de ritual que asume la acción cotidiana, como el vestirse o encender el cigarro; la satisfacción que experimenta con las palabras de la Santiaguera, a manera de plegaria elevada a través de una intermediaria; la humillación del rival; todo está en función de que más que a un rey, se le compare con un dios.

Es muy probable que Carlos Felipe tuviera presente que los personajes de la antigua tragedia eran dioses, héroes, reyes; pero sobre todo la creencia tan arraigada entre los antiguos griegos de que el ser humano no debe traspasar los límites que le separan del dios, so pena de atraerse la ira y el castigo de los todopoderosos. Recordemos el rechazo de Agamenón, en la tragedia esquilea de este nombre, a que se le rindiera honores solo tributables a los dioses y la insistência de Clitemestra, conocedora de que esta actidud de moderación era sólo una máscara 
y su deseo de que diera muestra pública de hýbris, al ser tratado como un dios, para justificar el crimen que planeaba; o a Edipo, saludado por el coro como hijo de la fortuna, rey de dos ciudades, momentos antes de convertirse en el más desgraciado de los hombres al conocer su verdadera identidad.

Resalta también en esta caracterización del personaje que, al explicitar su excelencia, su areté, para emplear el término de los antiguos griegos, Yarini haga descansar la misma en su "entereza, acción, hombría", en sua valentía, tal como ocurría con los héroes homéricos, aunque su enemigo insista en el "pico de oro", su facilidade de palabras; y si bien sabemos que Fénix educaba a Aquiles no sólo para acometer grandes proezas sino para hablar bien, como sinónimo del arte de gobernar, en boca de Lotot, bajo el cumplido -pues también para el proxeneta la elocuencia es parte integral de la posición que ostenta-, yace cierto aire de sorna que apunta a subrayar la apariencia. Por ello, aún sin rechazo expreso, Yarini procura hacer pasar a un segundo lugar la cualidad resaltada por su enemigo.

Para completar el paralelo, también para estos proxenetas es la fama la mayor recompensa, aunque de nuevo se juegue con la ambivalencia entre la evocación heroica y la mezquindad imperante, cuando Lotot, a la manera de Néstor, magnifica el pasado al reconocer que ya no hay héroes como los de antaño: "se relata hazañas casi increibles", se jacta el tahúr, "en esta época de polvo y fango. Porque ya no hay héroes" (Carlos Felipe, p.215). La jactancia y la autoafirmación de los antiguos héroes está también en esta "aristocracia" del hampa, pero, más que la identidad, se siente la diferencia.

Ahora bien, en este ambiente de valores consolidados, al parecer, y por tanto monolítico, no deja de existir fisuras, hecho anticipado en la leontina, con su alegoría de un anhelo superior cuya satisfacción reclama el justo pago, y que Yarini vincula inmediatamente con la Santiaguera, al hacer de ambas el premio indivisible en el primer enfrentamiento, agón sería el término clásico, con su rival: agón que, por demás, se interioriza y muestra donde reside realmente el conflicto en el monólogo que preside la decisión de Yarini sobre el número de la charada y cuyo desenlace está por el momento en manos del azar. El personaje duda, no solo por la charada o por su prestigio, sino porque, como ya había intuido la Jabá, la Santiaguera, le importa mucho más que lo que a sí mismo se admite, y ello implica su propia negación como arquetipo de chulo.

Los peligros que amenazan a Yarini ya no solo son externos, ni estipulados po el orden superior, sino también están dentro de él y pueden conducirlo a transformarse en su opuesto, tal como Sófocles comprendía el error trágico. Apuntado el conflicto, Yarini pierde la charada, la Santiaguera se aleja y la Jabá extiende su mano protectora. Por el momento el peligro parece conjurado y, al comenzar el segundo acto, el encuentro de Yarini con la Dama del Velo parece confirmarlo. De nuevo se abre un paréntesis equivalente en cierta medida a la función del stásimon que sucede al episodio en la estructura trágica, similitud reforzada por la introducción del elemento musical con el danzón que bailan ambos personajes.

De la Dama del Velo, Carlos Felipe ha apuntado que tiene su antecedente en el personaje de Lucía en Esta noche en el bosque, obra escrita en 1933 y donde prefigura elementos que caracterizan su quehacer posterior como teatrista: "el contrapunto entre el mundo marinero y marginal... con el mundo de la burguesía, con la consabida reconstrucción de los sucesos amorosos mediante la memoria", "la presencia del mar como elemento de desaparición o de encuentro" y la búsqueda de "la emoción ante el hombre", presente está en la Lucía del acto III de esa primera obra, y en la Dama del Velo.

Esta emoción buscada por la Dama, sirve de nuevo para reafirmar la imagen de Yarini. No es amante, no es conquistador: es chulo; pero al tiempo brinda la autodefinición de Yarini como ente vivo, y según afirma, para él "vivir es marchar en línea paralela a mis inclinaciones". Al igual que ocurría con la primera intervención de la Dama, que ponía de relieve las normas que hacen posible la existencia del orden por el cual Yarini es significativo, esta segunda aparición subrayaba 
el carácter del vínculo creado, antes visto desde la óptica de las mujeres, ahora desde el otro polo, el del proxeneta. Como cualquier stásimon coral, marca el espacio entre las acciones, implica una distensión y un momento propicio a la reflexión sobre la índole de lo que contemplamos en la escena.

La vuelta de Lotot renuda la acción. La aparente solución del fin del primer acto, que dejaba indemne el mundo de la Jabá, no ha sido más que, como en Sófocles, un paso que acerca el momento decisivo. Sin embargo, por un momento los principios que rigen este mundillo parecen reafirmarse y culmina la glorificación del proxeneta, cuando Yarini proclama que "el souteneur tiene mucho de un dios que sintiera compasión por los hombres".

En el nuevo enfrentamiento entre Yarini y Lotot, este último, aunque todavía se afirma en las normas no escritas de comportamiento que priman en su círculo de relaciones, tiene que confesar su propia relegación y la primacía de su rival, al admitir su conversión de dominador en dominado; pero, por lo mismo, más fiero y más dispuesto a verter sangre en defensa de su propiedad, puesto que no por amada la mujer ha dejado de ser considerada como objeto.

Una y otra vez frente a la intensión declarada de Lotot de derramar la sangre de Yarini, si llegara al caso, la Jabá opone su propia determinación de que ello no ocurra, pero también, en sus apartes, va develando lo que se oculta tras la aparente indiferencia y jactancia de Yarini. Le brecha no es tanta como supone Lotot. En el primer encuentro de ambos rivales Yarini había percibido, aunque no lo admitiera, lo que para él significaba la Santiaguera, ahora los estremecimientos de Lotot lo sitúan de nuevo, como en la alegoría de la leontina, ante la puerta de anhelos latentes de algo distinto, superior; lo llenan de envidia, y se traiciona, al rechazar, al unísono con su rival, los insultos de la Jabá a la Santiaguera.

Por ello, cuando glorifica la misión del proxeneta y se comporta como un dios, se pone de manifesto, como tantas otras veces en la obra sofoclea, la futilidad de las ilusiones humanas, que cobra su mayor expresión en la oda de júbilo que usualmente en Sófocles precede a la caída del héroe, lugar que ocupan en el Réquiem las alabanzas de Ismael Prado a la valentía de Yarini, rubricadas por las mujeres, en una especie de kommós o diálogo lírico, a manera de nuevo stásimon, después de haber anunciado Ismael lo inminente del golpe proveniente de Palacio.

Más no solo el recuerdo de antiguas glorias llena esta suerte de interludio, con la intervención de las mujeres a coro, sino que la evocación de las antiguas contiendas provoca la reflexión de Yarini sobre la vida y la posibilidad de que también la muerte sea bella al indentificarla con la Macorina, famosa cortesana, ya muerta, cuya belleza desafiante en los para entonces raudos automóviles, recién llegados a las calles de La Habana, fue en su momento foco de atracción y motivo de leyenda. La búsqueda de una emoción particular, que antes se apreciaba en la Dama de Velo, va a proyectarse en esta mujer que fuera reina donde ahora Yarini es rey. Pero Yarini no puede morir, concluyen las mujeres e Ismael. La evocación es rechazada y el proxeneta deseoso de vivir, se refugia en el amparo de la Jabá ante su propia debilidad: el dios es humano y por ello la Jabá a veces se siente diosa.

La parte final del segundo acto-tercer episodio de seguir el esquema organizativo de la antigua tragedia- hace patente el designio divino, del que ya había dado anuncio Bebo la Reposa en los inicios de la obra. La Guerrera, Changó, se ha pronunciado, pero la decisión última recae en el ser humano, quien ha de asumir la responsabilidad de su opción y lo que ella comporta.

Podrá salvar la vida Yarini, si sale inmediatamente de La Habana y no vuelve hasta que la Guerrera autorice su regreso; siempre que a partir del momento del despojo, no vuelva atrás la cabeza hasta el día siguiente. También Ayax, en la tragedia de Sófocles de igual nombre, podrá salvar la vida, según se ha pronunciado el oráculo, si logra rebasar el plazo de ese día. El no mirar atrás es también precepto bíblico para quienes fueron autorizados a escapar de la destrucción de Sodoma y Gomorra; pero los personajes de Carlos Felipe -Palma, Leonelo, Lisia, Pablo- están marcados por la necessidad de volver atrás la mirada para encontrarse a sí mismos, para auto- 
reconocerse, para completar su anagnorisis, si hemos de emplear el término griego.

Yarini, que anteriormente se ha sobrepuesto al anhelo de unión con la Macorina, única mujer capaz de pararse a su lado, como igual, acepta el designio y prepara la partida. Pero cuando parece que los augurios de muerte serán superados, la voz de la Santiaguera lo enfrenta al dilema, la opción fundamental que ha de asumir el héroe trágico. Al traspasar los límites, al buscar satisfacer ansias íntimas que poco a poco se habían puesto en evidencia y que en su condición de rey de los chulos le eran vedadas, Yarini alcanza ese momento vital que marca a los personajes de Carlos Felipe, pero sella su suerte. El espectro de la Macorina lo aguarda, ante el horror de la Jabá.

La Jabá, en su desesperación, se resiste a aceptar lo inevitable; ante la negación de los poderes divinos, en boca de Bebo la Reposa, se rebela y al comprender que ya no es parte de estos, sino que la sobrepasan, solo pide morir primero. Escena esta con la que el dramaturgo suplanta el comentario lírico-coral de la tragedia griega, subraya la dimensión de la decisión tomada y abre el tercer acto. El anuncio de la cercanía de los esbirros de Palacio, reanuda la acción. Yarini ha quebrado las normas, pero no deja de pertenecer a este mundo cuyo fin avizora la Jabá con la muerte de su rey, de tal modo que sus palabras, su última invocación a la divinidad, una vez resignada, es un treno, un canto de dolor, tanto por uno como por el otro. No hay palabras, se lamenta la Jabá, para expresar la desolación en que caerá el mundo si falta Yarini.

Pero antes del enfrentamiento final con Lotot, la presencia de la Macorina, a manera del deus ex machina al que Eurípides era tan adicto y Sófocles adoptó en algunas de sus obras, hace explícito cómo la Santiaguera ha sido un instrumento y cómo el ansia de Yarini se remonta más allá de esta mujer, en que por momentos se concreta. Por eso no olvida el dije de la leontina antes del encuentro decisivo de Lotot y lo reclama ya moribundo.

Los temores de la Jabá al principio de la obra se han cumplido; el amor de la Santiaguera ha sido el detonante, las amenazas de Palacio han precipitado la acción y los sucesivos enfrentamientos con Lotot han ido marcando la peripecia, el cambio de fortuna de que hablaban los griegos. Solo queda ella, la Jabá, para entonar el réquiem final. Así, a manera de la distensión última que cierra toda tragedia griega ante la comprensión del orden esencial que subyace bajo la acción, es ella quien da fe del tránsito de Yarini, de la paz encontrada en su unión con la Macorina y la trascendencia, por tanto, de los límites prefigurados en la leontina, como representación de la fuerza, de la resistencia encerrada en un mundo que fue el suyo y que ha perdido su razón de ser.

La estructura de Réquiem por Yarini nos revela, por tanto, que Carlos Felipe tuvo en mente y cuidó de organizar su obra según el patrón establecido por la tragedia clásica. No contó con un coro, pero suple su presencia con partes de diálogos en contrapunto entre varios personajes -en un caso al menos con la responsión unánime del grupo de mujeres- y con otras, en que si bien sólo participan dos personajes, sí se aprecia el carácter de distensión y de expresión emocional, a la vez que proyecta una dimensión de lo expuesto en las partes alternas de acción propiamente dicha, y permite una mayor compresión de su significado; todas estas funciones desempeñadas, indudablemente, por las partes líricas, corales, de la tragedia griega. Se podría, por tanto, resumir en este esquema, la forma en que la obra se organiza:

\section{Primer acto:}

Prólogo. Presentación de la situación de conflicto.

Párodos. Dama del Velo-Jabá-Santiaguera. Condición de las mujeres.

Primer Episodio. Yarini, el rey. Primer agón con Lotot. Pérdida de la Santiaguera y la leontina.

\section{Segundo acto:}

Primer stásimon. Yarini-Dama del Velo. Condición del chulo.

Segundo Episodio. Fuga de la Santiaguera. Segundo agón con Lotot.

Segundo stásimon. Ismael y mujeres. Glorificación de Yarini. La Macorina y el deseo de vivir. 
Tercer Episodio. Oráculo. Agón íntimo de Yarini. Su opción.

\section{Tercer acto:}

Tercer stásimon. Bebo-Jabá. Desesperación de ésta.

Cuarto Episodio. Pertenencia de Yarini al mundo cuyas normas ha quebrado. Momento vital. Cuarto stásimon. Jabá-Bebo, Yarini-Santiaguera. La muerte de Yarini como fin de este mundo. La Macorina y la emoción buscada por Yarini.

Éxodo. Tercer agón con Lotot. Muerte de Yarini. Réquiem en boca de la Jabá.

Con toda la simplificación y estrechez que un esquema supone, sirve para percatarnos de cómo se ha procurado, a través de distintos recursos, más contemporáneos, mantener efectos semejantes a los suscitados por la secuencia de episodios y stásima, enmarcada entre el prólogo y el éxodo; agrupados estos con cierto balance simétrico en los tres actos de la pieza. Al mismo tiempo, se pone de manifiesto como el paradigma se mantiene, ya no en cuanto a la estructura externa se refiere, sino a la interna, a la organización de la tensión dramática, con su momento climático en la opción del héroe.

Aunque por comodidad teórica posiblemente, suele hablarse de tragedia griega como un todo, el propio quehacer de los tres grandes trágicos cuya obra se conserva, muestra la falacia de tal condición. Cada uno reformula el género y sus constantes, muchas de ellas de raigambre ritual, en función de la expresión de su propia cosmovisión trágica. No se puede hacer tabula rasa frente a la tragedia de Esquilo, Sófocles y Eurípides.

Aristóteles, el primero que teorizara sobre esta materia de modo sistémico, alguma vez llamó a Eurípides el más trágico de los trágicos, empleando el término con una acepción semejante a la usual entre nosotros, de sangriento y terrible, que ya tenía por entonces. Pero a la hora de elegir un modelo teórico, evidentemente seleccionó a Sófocles, con quién el género alcanza su madurez perfección. Também este es el punto de partida de Carlos Felipe, como se apuntara antes en diversas ocasiones, aunque de ello no dejara constancia, como si lo hiciera Virgilio Piñera en relación con su Electra.

$\mathrm{Al}$ igual que los héroes sofocleos, Yarini lleva en sí los factores de su propia destrucción, que se revelarán en la confrontación con otros personajes, recurso favorito también de Sófocles. La búsqueda de emociones, que también está en la Dama de Velo, el ansia de franquear los límites representados en el dije de la leontina y, tal como esta anuncia, la disposición a pagar el precio, aunque sea este la muerte, será el móvil de su negación y ruptura con el sistema de relaciones y valores que lo han erigido como rey, el cual, a su vez, sin él se derrumbará, a diferencia de las tragedias antiguas en la cual la acción del héroe redundará, de forma más o menos inmediata, en beneficio de la colectividad.

También, como en la visión trágica de Sófocles, el orden divino, susceptible de ser conocido a través de oráculo, actúa como trasfondo de la acción del héroe. Carlos Felipe ha aprovechado las creencias de santería, tan arraigada en muchos de los habitantes de barrios como el de San Isidro, para dar un paso más en el proceso de transculturación. El mandato de Atenea en el Ayax es ahora la ordem de Santa Bárbara-Changó, la Guerrera. Los ritos santeros actúan como vínculos y Bebo la Reposa asume la función de augur y sacerdote.

La caída del héroe está dentro del orden divino, pero es la decisión del hombre, de acuerdo con sus íntimas motivaciones, lo que se presenta en primer plano. Sin embargo, falta la visión antinómica de Sófocles, quien continuamente contrapone el quehacer del ser humano, librado a los límites y deficiencias de la percepción y el conocimiento de las apariencias, con el plano divino, considerado como la explicación última, el conocimiento esencial, las leyes verdaderas que el hombre busca descubrir. De ahí que, aunque Carlos Felipe adopte recursos como la salutación jubilosa y la glorificación que precede a la caída, con los que no solo se acentúa la magnitud de esta última, sino que se hace palpable lo futil de las ilusiones humanas, no pueda recorrir a la 
ironía trágica, que recorre y permea la producción de Sófocles en su totalidad como eficaz expresión de la oposición entre apariencia y realidad, implícita en la contraposición de la existencia humana frente a un orden más profundo, identificado por el trágico con la divinidad. Tampoco se encuentra la búsqueda de la comprensión de lo que constituye la esencia del hombre, constante sofoclea, aunque si el descubrimiento de la verdadera personalidad como individuo.

Peripecia y anagnórisis, recursos fundamentales de la tragedia según postulara Aristóteles, determinan la línea de desarrollo de la tensión dramática. Las escenas de agón, de lucha y debate, tan utilizadas por Eurípedes, desenpeñan un importante papel en la progresión de la acción y en la concepción total de la obra como agón vital, tal como el arte trágico supone entre los antiguos. La hýbris, las leyes no escritas, que el hombre debe acatar, el concepto de héroe, la confrontación con el plano divino, la opción consciente del riesgo y la asunción de lo que ello comporta, la importancia que adquiere el ser humano y sus motivaciones internas en la obra sofoclea, son, entre otros, aspectos de la antigua tragedia que Carlos Felipe no ha desdeñado usar en la configuración de su por tanto tiempo proyectada "tragedia griega cubana":

Al constatar el modelo sofocleo, viene a la mente la tajante declaración de Jacqueline de Romilly sobre que no hay otro teatro como el de este trágico: al tiempo que presenta los mayores sufrimentos, provoca sentimentos de admiración hacia el ser humano y de amor por la vida, por medio de la actuación del protagonista quien se esfuerza en pos de lo mejor, sentir que se reafirma en los cantos corales exaltantes de la belleza (Romilly, 1973, p.112-3).

Este efecto de la tragedia griega que Camila Henriquez Ureña asociaba con el lema de la Novena Sinfonía de Beethoven, "A la alegría a través del dolor", es indudablemente algo que hace cuestionarse sobre si en verdad Carlos Felipe alcanzó su propósito.

El hecho de que al publicarse la llamara, al igual que a sus otras obras, comedia, hace pensar si con ello quería subrayar la unidad de su quehacer teatral o si, a pesar de como concibiera el tema y su cuidadosa labor para plasmarlo, advertía las diferencias.

Aunque suele considerarse la comedia en las antípodas de la tragedia, en la antigua Grecia, en la obra de un comediógrafo como Menandro, de fines del siglo IV a.n.e., se observan las líneas de convergencia que entre ambos géneros se formaron en el curso del processo teatral y, de ahí la repercusión que ello tuviera en las poéticas peripatéticas posteriores, a partir de las ideas de su fundador Aristóteles.

La comedia fue conceptuada como una ficción relativa a acciones de la vida privada que contribuía a conciliar la vida. De ahí su reputación como imitación de la vida, espejo que costumbres, imagen verdadera. Este sentido subayace en las llamadas "comedias del alma" en la Edad Media,en que se representaba el viaje del alma por regiones de ultratumba en busca de su purificación. Fue este uno de los elementos, junto con el caráter popular otorgada por la lengua en que fue escrita y el final feliz, por los que Dante escogió el término Comedia para titular su obra.

También Carlos Felipe parece tomar el vocablo en concordancia con estos usos. No es de extrañar tampoco que con ello quisiera subrayar el empleo de personajes que nunca tuvieron cabida en la tragedia, aunque sí en la comedia; la condición de ficción, de creación de la trama, aunque partiera de un hecho histórico, como tantas veces se destacara en la comedia para diferenciarla de la tragedia, siempre apoyada en mitos de todos conocidos, y la fuerte presencia de elementos de una cultura popular que adquiere tintes de resistencia.

Si bien es verdad que cada uno de los tres grandes trágicos ofrece su propia variante, acorde a su compresión de lo trágico, no es menos cierto que de una forma u otra se manifesta como rasgo distintivo, el que en su acción el héroe se enfrenta a situaciones conflictivas, a obstáculos que impiden la realización de la sociedad y del hombre como tal. Ciertamente hay fallos en su obrar, pero ello no es óbice para que se sienta como un alto exponente de los valores humanos. El espectador comparte con él la experiencia vital en que se ha enfrascado. Como dijera Camila Henriquez Ureña: "el héroe cae herido, con frecuencia muere, pero su muerte nos mueve a 
la par a horror y alegría. Compartimos su suerte con amistad, con participación, como si constituyera a libertarnos también del destino". De ahí el efecto resultante del que antes se hablara y sobre el cual Aristóteles erigirá su teoría de la catarsis para reinvindicar el teatro frente a los ataques de su maestro Platón.

Es aquí donde se ha de buscar la principal diferencia, pues el mundo marginal de chulos y prostitutas tiene limites muy precisos. El propio personaje sella su suerte, al abrigar ansias de emoción de algo distinto; ello lo lleva a su negación como chulo y por tanto a la transgresión del código de comportamiento imperante. Con él, como asienta la Jabá, se hunde ese mundo de normas y mecanismos que lo hacen rey, y de ello estaba muy consciente Carlos Felipe cuando bautiza definitivamente su obra como réquiem. Para quién tan conocedor se muestra de la antigua tragedia, tanto en su técnica como en sus presupuestos conceptuales, el apartamiento voluntario de estos últimos ha de considerarse como una nueva y personal propuesta tan válida como la de tantos otros autores antiguos y modernos que se han afanado en pos del género trágico. Aún en la época clásica, Eurípedes se convirtió en piedra de escándalo al introducir nuevos personajes, no pertenecientes a las altas capas gobernantes, nuevos temas, nuevas inquietudes, y ofrecer obras en las cuales la tragedia estaba a punto de dar paso al drama, en el sentido moderno del término. En nuestro siglo baste recordar tratamientos tan disímiles como los de O'Neill, Anouilhe o Sartre.

Con gran pericia técnica y sensibilidad teatral, supo Carlos Felipe apropiarse de patrones esenciales de la antigua tragedia para procurar una nueva perspectiva del entorno de normas y valores que tan bien conoció en los barrios donde viviera por tantos años, y que por entonces, como lo hiciera notar su hermana Rosa, no se consideraba apropriado para un teatro "serio".

Quería Carlos Felipe un teatro cubano, pero no aceptaba reducirlo solo al tipo de obra que por la época en que empezara a escribir, se hacía en el Alhambra o en el Regina. La lectura del teatro que se lleva a escena en otras partes del mundo, lo entristecía en la medida en que le revelaba la distancia que mediaba entre uno y otro: pero, según cuenta, tambiém le servía de acicate para intentar abrir nuevos caminos.

No buscaba en el ámbito marginal en que había crecido los rasgos caricaturescos y superficiales que llamaban la atención a primeira vista, ni pretendía abundar con espíritu naturalista en los bajos fondos. Se interesaba por el ser humano y por aquello que lo identificara como tal, aún en la condición más deleznable; por llevar a sus obras, según sus palabras, lo que encontraba en su búsqueda por la entraña popular y lograr hacer un teatro que fuera cubano pero contemporáneo.

Percibe y procura apresentar lo que Graziella Pogolotti calificara como "la imagen de una cultura hecha para la supervivencia", y ello lo alcanza precisamente en su Réquiem por Yarini al conferirle a ese mundo una nueva dimensión en su proyección como tragedia. Lo fundamental por tanto, no es hasta qué punto logró o no escribir una "tragedia griega cubana", sino que junto a Virgilio Piñera y Rolando Ferrer dio un vuelco total a la escena cubana y sentó las bases de nuestra dramaturgia contemporánea.

\section{Notas}

1 - Todas las referencias que se hagan en lo adelante a palabras de Carlos Felipe se encuentran, a no ser que se exprese lo contrario, en una entrevista que Armando Suárez del Villar tituló De conversación con Carlos Felipe, y que nunca se ha publicado, pero cuyo manuscrito donó a los fondos de la Biblioteca del Teatro Nacional, en La Habana, Cuba. 
¿Una tragédia griega cubana?

\section{Referencias Bibliográficas}

CARPENTIER, A. La consagración de la primavera. La Habana: Ed. Letras Cubanas, 1979.

GARCÍA LORCA, F. Obras Completas. Madrid: Aguilar, 1962.

LEAL, R. En primera persona. La Habana: I.C.L., 1967.

POGOLOTTI, G. Prólogo. En: Teatro y Revolución. La Habana: Letras Cubanas, 1980.

CARLOS FELIPE. Teatro. La Habana: Ed. Unión, 1967.

ROMILLY, J. de. La tragédie grecque. Paris: P.U.F., 1973.

HENRÍQUEZ UREÑA, C. Orígenes del teatro griego. Conferencia dictada en la Universidad de La Habana, 1962.

CANCELA, Elina M. Réquiem por Yarini. Une tragédie grecque cubaine? Classica, São Paulo, 7/8:317-328, 1994/1995.

RÉSUMÉ: Carlos Felipe (1914-1975) est l'un des fondateurs de la dramaturgie cubaine contemporaine à côté de Virgilio Piñera et Rolando Ferrer. Mais, tandis que Piñera adopte directement le mythe comme sujet de sa première pièce (Electra Garrigó), Felipe mettra des années embrassant l'idée de ce que lui même a appelé "une tragédie grecque cubaine". La mort d'Alberto Yarini - fait et personnage historiques dévenus légende des faubourgs qu'il connaît si bienlui sert à fixer un point de départ au déroulement de son entreprise. Dans cette étude on analyse de quelle manière Carlos Felipe fait devenir le sujet en mythe, le mode choisi pour structurer sa pièce d'après les règles de la tragédie, ainsi que les ressources et les concepts employés pour réussir dans ce but. Bref, cette étude cherche à comprendre surtout comment l'auteur provient à accorder à Réquiem por Yarini une place d'importance dans l'anthologie du théâtre cubain. MOTS CLES: Carlos Felipe, Réquiem por Yarini, tragédie grecque, théâtre cubain, littérature comparée. 